\title{
Work outcomes in family-aided assertive community treatment: vocational rehabilitation for persons with psychotic disorders
}

\author{
WILLIAM R. MCFARLANE, ROBERT DUSHAY, ELLEN LUKENS, PETER STASTNY, \\ SUSAN DEAKINS, BRUCE LINK
}

\begin{abstract}
Although there is still controversy about the ultimate wisdom of deinstitutionalization, states generally are continuing to implement this policy (Gralnick, 1985; Okin, 1985; Minkoff, 1987; Lamb, 1991). Hospital census continues to decline and the present mental health agency administrations of most states and countries have embarked on major initiatives to develop treatment and rehabilitation capacity in the local community for the severely mentally ill (SMI) (Bachrach, 1991). Central among these is an emphasis on psychiatric rehabilitation as a core element in the treatment philosophy and in the everyday practice of all clinicians who deal with the SMI population.
\end{abstract}

During the recent era of deinstitutionalization, as community support programs have become increasingly effective in preventing rehospitalization, interest in rehabilitation of the stable, but poorly functioning, mentally ill patient has increased. One perspective on rehabilitation is to divide existing approaches into two categories. In the first, the "conventional vocational rehabilitation» (CVR) model, patients are referred to relatively large, specialized sheltered workshops and vocational training programs, reflecting rehabilitation methods used in state hospitals before deinstitutionalization or approaches adapted from rehabilitation of the physically disabled. These have generally been discrete facilities, in which psychiatric treatment and case management are provided by another, separate mental health clinic. These services have tended to assume that many mentally ill persons will be unable to participate in competitive jobs. One

Indirizzo per la corrispondenza: Professor W.R. McFarlane, Maine Medical Center, Department of Psychiatry, 22 Bramhall Street, Portland, Maine (USA).

Fax: + 1-207-871.2091.

E-mail:mcfarw@mail.mmc.org unintended effect of this approach is to congregate patients and to keep them separated from normal work-places. Increasingly, many such programs now define this type of rehabilitation as time-limited and preparatory to competitive job placement. The efficacy of this approach has continued to be less than might be desired. Utilization by the SMI of conventional vocational training services has declined in the years 1977-1984, as did the number of individuals who were rehabilitated or achieved competitive employment (Bond, 1992). Premature drop-out from conventional programs can run as high as $1 / 2$ of all applicants. Anthony et al. (1978), reviewing the literature, reported that maximum rates of successful job placement are in the $20-30 \%$ range.

The other major group of approaches to rehabilitation continues the conceptual thrust underlying deinstitutionalization: maximum possible community integration. These approaches, including transitional employment, supported employment and assertive community treatment, attempt to provide jobs in competitive settings and do whatever appears to be necessary to assist a patient to find, gain and retain normative employment. Thus, methods have included focussed skill training in job interviews, providing guarantees to employers of a worker, on-site job coaching, development of special positions suited to the mentally ill and integration and close coordination of clinical treatment and rehabilitation services. To a large degree, methods are determined by the creativity of the clinical team and local employment circumstances. Generally, these methods are individualized and do not involve congregation or segregation of the SMI. Recent studies, including one being conducted by the authors, support the efficacy of this orientation (Bond \& Boyer, 1988; Bond et al., 1997; Drake et al., 1996; Worrall \& Vandergoot, 1982; Vandergoot et al., 1983). 
The other major factor in the implicit debate between these overall models is relative costs, because sheltered work and vocational training programs offer an economy of scale and can even turn a modest profit to support clinical and other rehabilitation services. The integrative approaches are all inherently more expensive in the short run and depend on the patient's lower service utilization and ultimate earning power to achieve cost-effectiveness (Bond, 1984; Weisbrod et al., 1980). In short, they are fiscally riskier for the sponsoring agency.

An important example of the second type of rehabilitation was developed by Stein and Test, in the form of their Training in Community Living approach (Test \& Stein, 1980; Stein \& Test, 1980; Stein $\&$ Santos, 1998). Clinicians followed a small number of patients in the community after discharge from a state hospital to help them learn vocational skills by using actual work placements in the community as the site for acquiring, relearning and practicing them. Outreach, job coaching and development, tightly organized teamwork and proactive, highly individualized treatment and rehabilitation planning were among the key elements of the model (Olfson, 1990). The effects on rates of rehospitalization, daily functioning and work adjustment were all significant when compared to traditional hospitalization. Onthe-job training, high counselor contact and individualized placement planning, all key components of this form of rehabilitation, have been shown to yield better placement ratios (Bond et al., 1995; 1997; Knoedler, 1979; Test, 1995). There have been several replications of the model, in rural settings (Field et al., 1980), in an inner city (Drake et al., 1995), in mental health centers (Bond et al., 1988) and as a state-wide policy (Stein \& Ganser, 1983). More recently, Test et al. (1985) have been investigating effects of a refined version of this approach (Program of Assertive Community Treatment PACT) on young patients to determine if the early course of the illness might be altered.

Another treatment approach spurred by deinstitutionalization has been to educate, support and provide ongoing guidance to the family of the SMI. Although families are generally providing shelter and support for the majority of the $n$, they have not generally been included in the treatment process. In addition, research on expressed emotion (EE) (Brown et al., 1972; Leff \& Vaughn, 1985; Vaughn, 1989) has suggested that family tension and confusion, most of it due to lack of understanding about mental disorders, was a major factor in the frequent relapses and poor community functioning noted among the many SMI patients who live at home. These two realities - family as caretaker and family as a factor in relapse - led to the development of several treatment models, by Goldstein (1978), Falloon et al. (1984), Anderson et al. (1986) and Leff et al. (1990) that demonstrated remarkable and consistent effects on one and two year relapse rates. The psychoeducational (PE) family interventions, in well-designed experimental comparative trials with medicated schizophrenic samples, yiclded two year rates in the $10-30 \%$ range, while individual supportive treatment yielded rates from $60-90 \%$.

Similarly to ACT, family intervention appears to promote functional adaptation. Both Doane et al. (1985) and Hogarty et al. (1988) have found inverse correlations between expressed emotion and social adjustment. Kopeikin et al. (1983) noted remarkable stability and community adjustment among patients three to six years after their treatment in family crisis intervention. Falloon et al. (1992) found that over $50 \%$ of the patients in family behavioral management were competitively employed at the end of two years. Anderson et al. (1986) reported high rates of community participation - in work rehabilitation, competitive work or in school - during family psychoeducation. However, Hogarty et al. (1991) noted that relapse rates began to rise when patients were referred from family treatment to conventional rehabilitation programs. Thus, psychoeducation appears to foster rehabilitation, perhaps more substantially than conventional vocational rehabilitation.

These treatment strategies - ACT and family psychoeducation - at this juncture appear to be solidly established as effective in reducing relapse and enhancing community functioning. However, we argue here that each contains a crucial limitation: ACT has not adequately addressed family participation in treatment, while the family approaches have not dealt adequately with the mentally ill patient's rehabilitation needs.

In the original conception of ACT, the goal of the clinician was to decrease the patient's dependency on the family as part of the community adaptation effort. Patients were encouraged to live away from the family home and restrict their contact with family members, who usually were not included in the treatment effort. More recently, the Wisconsin group has made more of an effort to include family members, but not systematically and not as an integral part of the patient's rehabilitation. This appears to us to be an important deficiency, given the youth- 
ful age of typical community-based patients, the high probability of their living with family members and the beneficial effects of family psychoeducation.

The argument for a weakness in the family approaches is based largely on our clinical research experience and that reported to us by other family clinical researchers. These methods rely heavily on alterations in family affect, behavior and attitudes. When outcome is determined more by negative patient factors, such as poor vocational achievement prior to onset of illness or severely debilitating negative symptoms, family interaction, even if ideal, is less likely to positively affect course. On the other hand, these are factors that ACT specifically addresses. Also, because the family models conform to an outpatient therapy profile, they rely on conventional vocational rehabilitation services. If these are refused by the patient, rehabilitation is much less likely to occur. A reasonable conclusion, supported by our outcome data, is that a combination of ACT, with its assertive and out-reach orientation, and family psychoeducation addresses the respective deficiencies of each approach while retaining their efficacy.

An additional refinement is to carry out family intervention in a psychoeducational multi-family group (PEMFG), in which clinicians meet with several families and patients together. We propose that FACT, combining ACT, family PE and a MFG, adds another increment of effectiveness by enlarging the family's social network. Several studies (Pattison et al., 1979; Tolsdorf, 1976; Sokolovsky \& Cohen, 1981; Hammer, 1981; Erickson et al., 1989) have noted the restricted size of the social networks of schizophrenic patients and, in many cases, of their families and that the family's network decreases with duration of illness (Lipton et al., 1981; Anderson et al., 1984). Brown et al. (1972) reported an association between [a] family expressed emotion, [b] smaller family and network size and [c] risk for relapse. Granovetter (1973) and Dozier et al. (1987) found that rehospitalization was reduced for patients in moderate-to high-density networks. Restriction of network size usually leads to less instrumental support and less access to information that might aid treatment and rehabilitation efforts.

We interpret these network studies to mean that enhancing network size and density will enhance patient outcome. That view is supported by early clinical experience with multi-family group therapy spanning two decades, during which it accumulated a respectable record in uncontrolled trials (Berman, 1966; Lansky et al., 1978; Lurie \& Ron, 1972; Fal- loon et al., 1981). Reported relapse rates ranged from 0 to $21 \%$, approximating those achieved later by psychoeducational methods. Because techniques and assumptions varied widely among clinicians, the common element contributing to MFG efficacy was probably an increase in social and instrumental support occurring across family boundaries.

To summarize, reported empirical and clinical experience appears to support the following conclusions:

1. Both ACT and PE reduce tendencies to relapse in the SMI.

2. High relapse rates all but preclude functional adaptation.

3. Lowering relapse rates alone does not guarantee enhanced adaptation.

4. ACT improves adaptation through direct, in-vivo vocational skills training in the patient's actual community context.

5. PE improves adaptation through enhancing the family's coping skills, by enhancing family emotional support for the patient and by coordinating rehabilitative efforts between family and the clinical staff.

6. ACT is improved by adding a PE component, as is PE by adding a ACT component, especially when addressing the difficult task of assisting the SMI to find and retain employment.

7. Neither ACT nor PE significantly expand the patient's or the family's social network.

8. Social netwòrk factors are important correlates of illness outcome.

9. The MFG, by definition, expands the patient's and family's network.

10. FACT, by combining ACT and family PE in a MFG format, would be expected to yield better outcomes than conventional approaches or its constituent elements.

11. That superiority might carry over to outcome in vocational rehabilitation.

What follows are brief synopses of four clinical trials in which family psychoeducation or familyaided assertive community treatment (FACT) were tested by our research team and compared for clinical and vocational-rehabilitation outcome effects.

\section{BERGEN PINES OUTCOME STUDY (MCFARLANE ET $A L .$, 1995A)}

Design. The first experimental trial of the psychoeducational multi-family group (PEMFG) ap- 
proach was conducted as a three-cell random assignment study at the only receiving hospital in a suburban county in New Jersey. The three treatment groups consisted of psychoeducational single family treatment (PESFT), conventional multi-family therapy (FDMFT) and the PEMFG treatment. Sixteen patients were treated in the PEMFG cell, 17 in the PESFT cell and 7 received FDMFT. Cases were followed for four years, making this one of the longest psychosocial treatment outcome studies to date.

Relapse outcome. Relapse was defined as any episode of psychosis lasting 7 days or more. All such episodes required hospitalization. For the first two years in treatment, the sample as a whole exhibited a significant difference in community tenure $(t=7.57, p=0.001)$ between the in-treatment period (mean $=19.4$ months) and the two years prior to admission in the study (mean 7.7 months). Further analysis showed differences in the time to relapse between the PEMFG and the PESFT groups. At the one year point in treatment PEMFG had fewer relapses than the PESFT cell $(12.5 \%$ vs $23.5 \%$; $\mathrm{p}=0.06$ ); PEMFG-PESFT relapse outcome differences increased over time. Analysis using Cox's Proportional Hazards Regression model found that at four years after discharge PEMFG had a significantly longer time to first relapse than PESFT (Cox's coeff./std. err. $=2.09 ; \mathrm{p}=.01$ ). Final 4-year relapse rates were $50 \%$ for PEMFG, $76.5 \%$ for PESFT and $57.1 \%$ for FDMFT. This study suggests that the multi-family group has a significant effect on relapse - beyond that of psychoeducation which emerges slowly but increases over time.

Functional outcome. One of the principal variables used to measure patient community functioning was current employment/education status. At intake, $32.5 \%$ of all study patients were involved at the active level (full/part-time work, full/part-time sheltered workshop, student, homemaker) in the community. At two years, $51.6 \%$ were active, across all treatment types. Of the three treatment types, PEMFG registered the highest increases on this measure, but the differences were not significant.

\section{FAMILY PSYCHOEDUCATION IN SCHIZO- PHRENIA PROJECT (FPSP) \\ (MCFARLANE $E T A L .$, 1995B)}

Design. These results were promising but needed replication in a larger sample. Started in 1985, the FPSP utilized a two-cell design to experimentally compare two treatments, the PEMFG and psychoeducational single-family treatment (PESFT), over a two-year period. This created a design in which the key difference between treatments was the ongoing multi-family group and its associated social processes. The design also included random assignment, full specification of the test therapies, extensive training and ongoing supervision of experienced therapists by the project's supervisory staff, a standard-dose medication strategy and wide-ranging measurement of patient and family outcomes. To our knowledge, this study is the largest demonstration of psychoeducational family intervention and the first major experimental trial of multi-family groups.

Sample characteristics. The total sample consisted of 172 DSM-IIIR schizophrenic and schizoaffective patients and their families at six New York State public psychiatric facilities - five state hospitals and one municipal hospital. These six sites encompass nearly the entire range of the public-service patient population in terms of chronicity, race, ethnicity, social class, and geography. Each participating site assessed and treated 24-36 patients, depending on patient availability. There were no significant differences at baseline between the treatment conditions on any of the measured variables.

Relapse outcome. Relapse was defined as the reemergence or increase of overt psychotic symptoms, regardless of hospitalization status, and was determined by an independent rater who was blind to treatment cell. One year outcome for those patients experiencing their first relapse during treatment was determined: $19.0 \%$ of PEMFG cases relapsed during the first year as compared to $28.6 \%$ of PESFT cases. The relapse rates at two years were $31.0 \%$ for PEMFG and $40.2 \%$ for PESFT. Controlling for medication compliance, PESFT cases were at a $60 \%$ higher risk of relapse than PEMFG cases ($0.49, \mathrm{SE}=0.27, \mathrm{p}$ approx .06). Further, we found that both positive and negative symptoms decreased significantly $(\mathrm{p}<=0.001)$ over time. PEMFG patients had lower symptomatology for the full two years of the project, but this difference was not significant.

Functional outcome. At baseline, patient employment status was established for the previous six months and compared to the final six months of the two-year protocol. $20 \%$ of our sample were classified as «engaged in employment-related activity» during the six moths before entry into the project. This category includes full- or part-time employ- 
ment, sheltered work, housework, or attending school. For the final six months of the project, $31 \%$ of the sample were classified as engaged in employment-related activity, a significant improvement $\left(t_{(138)}=2.79, p<.01\right)$. The modality of treatment had little effect on employment, although cases assigned to PEMFG had a non-significantly higher level of employment activity at the end of the project $\left(34 \%\right.$ vs. $\left.28 \%, \mathrm{t}_{(139)}=0.76, \mathrm{~ns}\right)$ and a greater gain in employment ( $16 \%$ vs. $8 \%$ ).

This increase in employment activity was mostly an increase in sheltered work: 3 cases $(2 \%)$ were engaged in sheltered work at entry into the project, while $15(9 \%)$ were in sheltered work at the twoyear assessment.

\section{FAMILY-AIDED ASSERTIVE COMMUNITY TREATMENT (FACT) STUDY (MCFARLANE ET AL., 1996)}

Design. The Family-aided Assertive Community Treatment (FACT) research project was initiated to test the efficacy of combining family psychoeducation with the already proven ACT model. There were two levels of family involvement. The intense involvement cohort combined ACT treatment with psychoeducational multi-family therapy (FACT). The low-intensity cohort combined ACT with limited single-family crisis intervention (ACT). It was hypothesized that FACT would lead to higher levels of vocational and social functioning than ACT alone, as a function of the supports and clinical problem-solving that are inherent in FACT. Assessments were made at four month intervals for vocational outcome.

Sample Characteristics. The total sample consisted of 68 patients at three Community Mental Health Centers in New York State. Patients were selected who met the following criteria: schizophrenic diagnosis (DSM-IIIR schizophrenia, schizophreniform and schizoaffective disorders); presence of at least one associated complicating factors (ACFs) (homelessness, non-compliance, substance abuse, criminal charges, suicidality); family availability; and age (18-45). Minor differences were found between the two cohorts on baseline psychiatric and demographic data.

Rehospitalization Outcome. Hospitalizations declined from a pre-treatment mean of 1.85 hospitalizations per patient in the two years prior to treatment to a mean of 1.37 hospitalizations per patient during the two years of treatment $\left(\mathrm{t}_{(52)}=2.89, \mathrm{p}\right.$ $<.01$ ).

Functional Outcome. Patients were considered engaged in employment-related activity if they were working at any job, whether full-time, part-time, or in a sheltered workshop. We found no difference in activity between the two cohorts at intake $(11 \%$ of FACT patients were engaged in employment activity, vs. $6 \%$ of ACT patients, $t_{(66)}=0.62$, ns). Employment activity for the total sample showed an increase in the first four months of treatment (repeated measures MANOVA, four-month intervals: $F_{(1,52)}$ $=8.54, \mathrm{p}<.01$ ) (figure 1). Patients were able to maintain this level for nearly the duration of the project. The maximum level of employment activity was $33 \%$, achieved at the 20 month assessment point. Unfortunately, after achieving this peak level, activity dropped off significantly in the last four months of treatment, to $17 \%\left(\mathrm{~F}_{(1,52)}=9.18, \mathrm{p}<.01\right)$. Most patients maintained their status from month to month. Of patients who working at one level at one assessment, most (72\%, non-sheltered; $69 \%$, sheltered; and $68 \%$, unemployed) were still doing that level of work four months later. Virtually all patients who left sheltered work after the 16 month point were subsequently unemployed.

For those patients who made a transition between assessment points, sheltered work was a preferred goal for the unemployed $(24 \%$, vs. $8 \%$ who engaged in non-sheltered employment activity). Few of those who had been engaged in activity outside of the sheltered workshops retreated to sheltered work $(6 \%$ vs. $22 \%$ who simply became unemployed). Patients in sheltered work were equally likely to move on to non-sheltered activity or become unemployed (15.5\% for each). Sheltered work seems to act as a buffer in moving from unemployment to unsheltered work, but few who are already employed would retreat to it.

Finally, we compared FACT and ACT treatment cohorts, using employment activity averaged across the duration of treatment. $18 \%$ of patients in FACT were in sheltered work, compared to $6 \%$ of the ACT sample $\left(\mathrm{t}_{(51)}=1.99, \mathrm{p}=.05\right)$; there was no difference for non-sheltered activity $(10 \%$ achieved new non-sheltered work activity regardless of family involvement).

These outcomes demonstrate that among a variety of schizophrenic subtypes, including severely dysfunctional and initially non-compliant schizophrenics, MFGs facilitate employment more effectively than single-family psychoeducational treatment or 
Work outcomes in family-aided assertive community treatment: vocational rehabilitation for persons with psychotic disorders

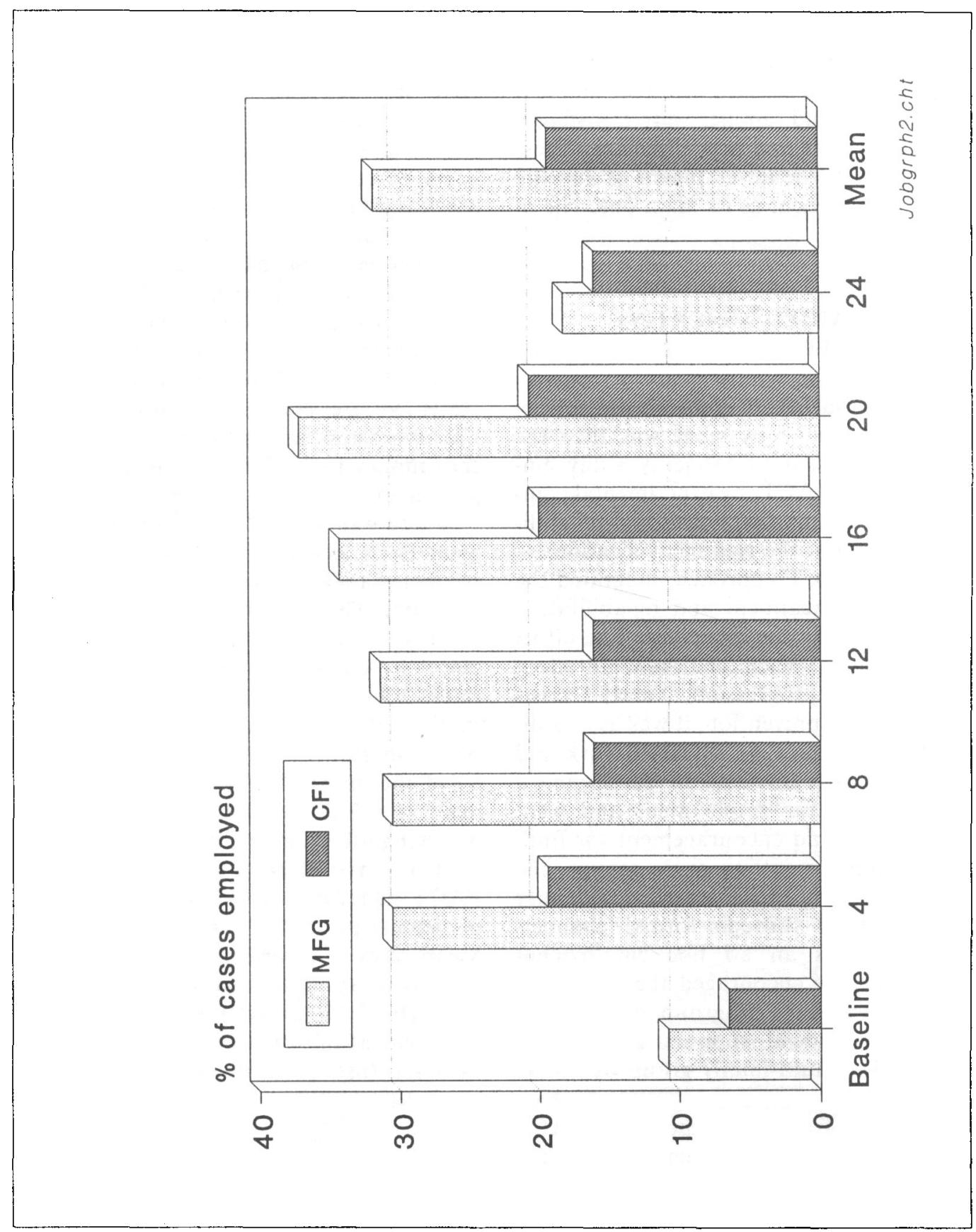

Epidemiologia e Psichiatria Sociale, 8, 3, 1999 
crisis oriented family intervention and ACT. These promising results are qualified by the fact that most of the employment held by patients was of the sheltered type, something many patients find undesirable. Because employment was not the main thrust of these studies, it is possible that the therapists did not actively attempt to wean patients from sheltered workshops and into more productive activities. Further, termination of the project at two sites may have contributed to deterioration in employment rates, as patients and families were transferred to less intensive programs and new clinicians. These residual concerns led to the development of another study which has employment as its main outcome of interest.

\section{WORK IN FAMILY-AIDED ASSERTIVE COMMUNITY TREATMENT (WORK IN FACT)}

Design. The Work in FACT research project began in April, 1991, funded by what was then the NIMH. It was undertaken to explicitly study employment outcomes for FACT, by experimental comparison to the best conventional vocational rehabilitation (CVR) available at the treatment locations.

In this study, the FACT approach integrated the family in the ongoing treatment and rehabilitation work being conducted by the clinicians. The effort was focussed on patient vocational rehabilitation, step-wise functional progression, early crisis intervention and relapse prevention; it was as coordinated as possible with the FACT team's work and plans. The families were involved in developing a consensus about goals for employment and went on to provide support and encouragement for finding and keeping employment. In some groups, the informal network in the MFG served to identify job leads not available through formal channels and actually served as an ad hoc employment agency. For families, we encouraged the expansion of their social networks by in-group cross-family problem solving and social support and out-ofgroup socializing. The multi-family group treatment is described in detail in a treatment manual which is available on request from the authors; the FACT approach has been described elsewhere (McFarlane et al., 1992).

Assessments of employment activity were made every three months. It was hypothesized that FACT patients would be more likely to be engaged in competitive (i.e., non-sheltered) employment than CVR patients. Results reported here are for the first 18 months of treatment and rehabilitation effort, a period of time probably too short for the full hypothesized effect to be seen, but the findings are promising.

Sample Characteristics. The total sample consisted of 69 patients at two community mental health centers in New York State. Patients were selected on the following criteria: diagnosis (DSMIIIR schizophrenic spectrum and affective spectrum), family availability, and age (18-55). Patients were randomly assigned to FACT and CVR cohorts, 37 to FACT, and 32 to CVR. A Mann-Whitney Rank Sum test showed no differences in employment at baseline 0.01 , ns).

Functional Outcome. Employment activity was broken down into four categories: unemployed, sheltered and supported employment, volunteer work, and competitive employment. The last category included a variety of tasks, such as gardening, making crafts for sale, and working for a regular employer. The only requirements were that the patient actually earn money by performing the activity and that the job was open to those without a mental illness.

There was a significant improvement in employment from baseline to 12 months for both groups combined (Wilcoxon Signed Ranks test: $z=2.58$, $p<.01$ ). The categories with the greatest improvement were volunteer work and competitive employment. FACT and CVR were then analyzed separately to determine how they changed over time. FACT patients showed a clear improvement in employment status $(\mathrm{z}=2.80, \mathrm{p}<.01)$, and virtually all of the improvement was in competitive employment $(F=9.21, p=0.004)$ (table I). CVR showed no change for the first 12 months of the project ( $\mathrm{z}$ $=0.37$, ns). Results at 18 months are similar: FACT had $24 \%$ of the cohort in competitive employment vs. $6 \%$ in CVR $(F=5.11, p=0.028)$. Mean rates of competitive employment over the 18 months were significantly higher in FACT than CVR $(F=7.72, p=0.007)$. Interestingly, the overall employment (all types) difference narrowed to $56 \%$ vs. $44 \%$ (ns), primarily through increases in noncompetitive employment in CVR.

\section{CONCLUSION}

In an effort to capitalize on the specific advantages and efficacies of ACT, multi-family groups and family psychoeducation, we have combined 
Table I. - Change in employment status over time, by treatment type.

\begin{tabular}{|c|c|c|c|c|}
\hline & FACT & & CVR & \\
\hline & Intake & 12 Months & Intake & 12 Months \\
\hline Unemployed & $69 \%$ & $35 \%$ & $69 \%$ & $45 \%$ \\
\hline $\begin{array}{l}\text { Sheltered \& } \\
\text { Supported } \\
\text { work }\end{array}$ & $17 \%$ & $14 \%$ & $19 \%$ & $19 \%$ \\
\hline $\begin{array}{l}\text { Volunteer } \\
\text { jobs }\end{array}$ & $3 \%$ & $11 \%$ & $3 \%$ & $10 \%$ \\
\hline Paid work & $11 \%$ & $35 \%$ & $9 \%$ & $3 \%$ \\
\hline Dropped out & t $0 \%$ & $5 \%$ & $0 \%$ & $23 \%$ \\
\hline
\end{tabular}

them in a more comprehensive treatment system, $F a$ mily-aided Assertive Community Treatment. Throughout, the aim is that the multi-family group become something of a task force, in which experts from various sectors of the patient's total network share experiences, information, planning, and the exploration of new ideas and options, especially in the difficult area of vocational rehabilitation. The ACT team's professionals' job is then to take these possibilities and attempt to realize them, working in natural settings to assist patients to find and keep mainstream employment. The assumptions are that all aspects of the patient's network should be brought to bear on the effort toward employment and that expanding that network through the natural connections in a multi-family group can gain each patient access to a greatly expanded pool of jobs, personal support and opportunities. This total process is a major contributor to the higher employment rates achieved to date in our experimental clinical trials of the FACT approach. As is evident in the outcome data, there is still a significant gap in our ability to assure successful rehabilitation of the majority of patients with severe and persistent psychotic disorders. The results are promising but still less than might be hoped. Also, the results suggest that it is premature to terminate these services after 18 or 24 months. There is consistent evidence in the studies presented here and in those by Pasamanick et al. (1967), Stein \& Test (1980) and Hogarty et al. (1991) that these patients need prolonged support to achieve lasting clinical and rehabilitation results. Importantly, Test presented employment data from the PACT study at the 1994 Annual Meeting, showing that over $70 \%$ of their sample's schizophrenic patients were competitively employed after seven years. While that is a long period of treatment and rehabilitation effort, it is highly promising that such high rates of community integration can occur at all. The studies presented herein all are consistent with the Test's groups results; that is, that about $10-15 \%$ per year of schizophrenic patients will achieve competitive employment, if offered ACT and/or family psychoeducation with a rehabilitation focus, as well as maintenance antipsychotic medication.

\section{REFERENCES}

Anderson C., Hogarty G., Bayer T. \& Needleman R. (1984). Expressed emotion and social networks of parents of schizophrenic patients. British Journal of Psychiatry 144, 247-255.

Anderson C., Reiss D. \& Hogarty G. (1986). Schizophrenia and the Family: A Practitioner's Guide to Psychoeducation and Management. Guilford Press: New York.

Anthony W.A., Cohen M.R. \& Vitalo R. (1978). The measurement of rehabilitation outcome. Schizophrenia Bulletin 4, 365-383.

Bachrach L.L. (1991). Service planning for chronic mental patients: some principles. International Journal of Group Psychotherapy 41, 23-31.

Berman K.K. (1966). Multiple-family therapy: its possibilities in preventing readmission. Mental Hygiene 50, 367-370.

Bond G.R. (1984). An economic analysis of psychosocial rehabilitation. Hospital and Community Psychiatry 35, 356-362.

Bond G.R. (1992). Vocational rehabilitation. In Handbook of Psychiatric Rehabilitation (ed. R.P. Liberman), pp. 244-263. MacMillan: New York.

Bond-G.R. \& Boyer S.L. (ed.) (1988). Rehabilitation Programs and Outcomes. Johns Hopkins Press: Baltimore, MD.

Bond G.R., Dietzen L.L., McGrew J.H. \& Miller L.D. (1995). Accelerating entry into supported employment for persons with severe psychiatric disabilities. Rehabilitation Psychology 40, 91-111.

Bond G.R., Miller L.D., Krumwied R.D. \& Ward, R.S. (1988). Assertive case management in three CMHCs: a controlled study. Hospital and Community Psychiatry 39, 411-418.

Bond G.R., Drake R.E., Mueser K.T. \& Becker D.R. (1997). An update on supported mployment for people with severe mental illness: a review. Psychiatric Services 48, 335-346.

Brown G.W., Birley J.L.T. \& Wing, J.K. (1972). Influence of family life on the course of schizophrenic disorders: A replication. British Journal of Psychiatry 121, 241-258.

Doane J., Falloon I., Goldstein M. \& Mintz J. (1985). Parental affective style and the treatment of schizophrenia. Archives of General Psychiatry 42, 34-42.

Dozier M., Harris M. \& Bergman H. (1987). Social network density and rehospitalization among young adult patients. Hospital and Community Psychiatry 38, 61-64.

Drake R.E., Becker D.R. \& Bebout R. (1995). In American Psychiatric Association Institute on Psychiatric Services, Boston, MA.

Drake R.E., McHugo G.J., Becker D.R., Anthony W.A. \& Clark R.E. (1996). The New Hampshire study of supported employment for people with severe mental illness. Journal of Consulting and Clinical Psychology 64, 391-399.

Erickson D.H., Beiser M.A., Iacono W.G., Fleming J.A.E. \& Lin T. (1989). The role of social relationships in the course of first- 
episode schizophrenia and affective psychosis. American Journal of Psychiatry 146, 1456-1461.

Falloon I.R.H., Lieberman R. \& Lillie F. (1981). Family therapy for relapsing schizophrenics and their families: a pilot study. Family Process 20, 211-221.

Falloon I.R.H., Boyd J. \& McGill C. (1984). Family Care of Schizophrenia. Guilford Press: New York.

Falloon I.R.H., McGill C.W. \& Boyd J.L. (1992). Family management in the prevention of morbidity in schizophrenia: social outcome of a two-year longitudinal study. Psychological Medicine 17, 59-66.

Field G., Allness D. \& Knoedler W. (1980). Application of the training in community living program to rural areas. Journal of Community Psychology 8, 9-15.

Goldstein M.J., Rodnick E.H., Evans J.R., May P.R.A. \& Steinberg M.R. (1978). Drug and family therapy in the aftercare of acute schizophrenics. Archives of General Psychiatry 35, 1169-1177.

Gralnick A. (1985). Build a better state hospital: deinstitutionalization has failed. Hospital and Community Psychiatry 36, 738-741.

Granovetter M. (1973). The strength of weak ties. American Journal of Sociology, 78, 1360-1380.

Hammer M. (1981). Social supports, social networks, and schizophrenia. Schizophrenia Bulletin 7, 45-57.

Hogarty G., McEvoy J., Munetz M., DiBarry A., Bartone P., Cather R., Cooley S., Ulrich R., Carter M. \& Madonia M. (1988). Dose of fluphenazine, familial expressed emotion, and outcome in schizophrenia. Archives of General Psychiatry 45, 797805.

Hogarty G.E., Anderson C. M., Reiss D.J., Kornblith S.J., Greenwald D.P., Ulrich R.F. \& Carter M. (1991). Family psychoeducation, social skills training, and maintenance chemotherapy in the aftercare treatment of schizophrenia, II: Two-year effects of a controlled study on relapse and adjustment. Archives of General Psychiatry 48, 340-347.

Knoedler W.H. (1979). How the training in community living program helps patients to work. New Directions for Mental Health Services 2, 57-66.

Kopeikin H., Marshall V. \& Goldstein M. (1983). Stages and impact of crisis-oriented family therapy in the aftercare of acute schizophrenia. In Family Therapy in Schizophrenia (ed. W.R. McFarlane), pp. 69-98. Guilford Press: New York.

Lamb H.R. (1991). Community treatment for the chronically mentally ill. Hospital and Community Psychiatry, 42, 117.

Lansky M., Bley C., McVey G. \& Botram B. (1978). Multiple family group as aftercare. International Journal Group Psychotherapy 29, 211-224.

Leff J. \& Vaughn C. (1985). Expressed Emotion in Families: Its Significance for Mental Illness. Guilford Press: New York.

Leff J., Berkowitz R., Shavit N., Strachan A., Glass I. \& Vaughn C. (1990). A trial of family therapy versus a relatives' group for schizophrenia Two-year follow-up. British Journal of Psychiatry 157, 571-577.

Lipton F., Cohen C., Fischer E. \& Katz S. (1981). Schizophrenia: a network crisis. Schizophrenia Bulletin 7, 144-151.

Lurie A. \& Ron H. (1972). Socialization program as part of aftercare planning. General Psychiatric Association Journal 17, 157162.

McFarlane W.R., Stastny P. \& Deakins S. (1992). Family-aided assertive community treatment: A comprehensive rehabilitation and intensive case management approach for persons with schizophrenic disorders. New Directions in Mental Health Services 53, 43-54.

McFarlane W.R., Link B., Dushay R., Marchal J. \& Crilly J. (1995a). Psychoeducational multiple family groups: Four-year relapse outcome in schizophrenia. Family Process 34, 127-144.

McFarlane W.R., Lukens E., Link B., Dushay R., Deakins S.A., Newmark M., Dunne E.J., Horen B. \& Toran J. (1995b). Multiple-family groups and psychoeducation in the treatment of schizophrenia. Archives of General Psychiatry 52, 679-687.

McFarlane W.R., Dushay R.A., Stastny P., Deakins S.M. \& Link B. (1996). A comparison of two levels of Family-aided Assertive Community Treatment. Psychiatric Services 47, 744-750.

Minkoff K. (1987). Beyond deinstitutionalization: a new ideology for the postinstitutional era. Hospital and Community Psychiatry 39, 945-950.

Okin R. (1985). Expand the community care system: deinstitutionalization can work. Hospital and Community Psychiatry 36, 742-745.

Olfson M. (1990). Assertive community treatment: An evaluation of the experimental evidence. Hospital and Community Psychiatry 41, 634-641.

Pasamanick B., Scarpetti F. \& Dinit S. (1967). Schizophrenics in the Community: an Experimental Study in the Prevention of Hospitalization. Appleton-Century-Crofts: New York.

Pattison E., Llama R. \& Hurd G. (1979). Social network mediation of anxiety. Psychiatric Annals 9, 56-67.

Sokolovsky J. \& Cohen C.I. (1981). Toward a resolution of methodological dilemmas in network mapping, Schizophrenia Bulletin 7, 109-118.

Stein L.I. \& Ganser L.J. (1983). Wisconsin's system for funding mental health services. New Directions for Mental Health Services $18,35-32$.

Stein L.I. \& Santos A.B. (1998). Assertive Community Treatment of Persons with Severe Mental Mllness. Norton: New York.

Stein L.I. \& Test. M.A. (1980). Alternative to mental hospital treatment I: Conceptual model, treatment program and clinical evaluation. Archives of General Psychiatry 37, 392-397.

Test M.A. (1995). In American Psychiatric Association Institute on Psychiatric Services, Boston, MA.

Test M.A. \& Stein L.I. (1980). Alternatives to mental hospital treatment, III. Social cost. Archives of General Psychiatry 37, 409-412.

Test M.A., Knoedler W.H. \& Allness D.J. (1985). The long-term treatment of young schizophrenics in a community support program. New Directions for Mental Health Services 26, 17-27.

Tolsdorf C. (1976). Social networks, support and coping: an explanatory study. Family Process 15, 407-417.

Vandergoot D., Maiman-Reich B. \& Murphy G. (1983). Increasing the Motivation of Job Searchers. Human Resources Center: Albertson, NY.

Vaughn C. (1989). Expressed emotion in family relationships. Journal Child Psychology Psychiatry 30, 13-22.

Weisbrod B.A., Test M.A. \& Stein L.I. (1980). Alternative to mental hospital treatment. II. Economic benefit-cost analysis. $A r-$ chives of General Psychiatry 37, 400-405.

Worrall D. \& Vandergoot D. (1982). Additional indicators of nonsuccess: A follow-up report. Rehabilitation Counseling Bulletin $26,88-93$. 